\title{
FOME DE VIVER: UMA ANÁLISE IMAGÉTICA DO VESTUÁRIO DE JOHN (DAVID BOWIE)
}

\section{HUNGER OF LIVING: AN IMAGETIC ANALYSIS OF JOHN'S APPAREL (DAVID BOWIE)}

\author{
Arthur Rodrigues da Silva ${ }^{1}$ \\ Márcia Taísa da Silva ${ }^{2}$
}

\section{INTRODUÇÃOO}

Fome de Viver (The Hunger) se passa em Manhatam, e retrata o relacionamento do casal Blaylock, um casal de vampiros. Miriam (Catherine Deneuve) é uma vampira que se mantém jovem ao consumir o sangue de seus parceiros, os mesmos após ter tido uma grande quantidade de sangue absorvido por Miriam começa a envelhecer de forma acelerada; desesperado por ajuda John (David Bowie) vai a procura da doutora Sarah Roberts (Susan Sarandon) uma especialista em envelhecimento precoce. No desenrolar da história a doutora Sarah acaba por se envolver com Miriam, a qual tem um destino trágico.

Dirigido por Tony Scott, o filme traz uma áurea sombria que circunda os personagens principais. O diretor até então fazia trabalhos na área de publicidade e propaganda, destinadas a comerciais televisivos e clips musicais, este fato é demonstrado na estética do filme, que possui uma fotografia escura, somada a alguns elementos de cena que compõem o exagero, além de algumas inserções de aparições da banda punk Bauhaus, que canta a música Bela Lugosi' s dead, um hino gótico sobre o vampirismo. Com figurino produzido por Milena Canonero (conhecida por seus trabalhos com Kubrick) e premiada com o Oscar por seus figurinos no filme Carruagens de fogo (1981), os personagens se apresentam com uma indumentária típica da subcultura gótica, e dos jovens Yuppies. Há uma parceria com Yves

\footnotetext{
1 Bacharel em Design pela Universidade Federal de Pernambuco/ Centro Acadêmico do Agreste. e-mail: arsilva1939@gmail.com

2 Graduanda em Design na Universidade Federal de Pernambuco/ Centro Acadêmico do Agreste. e-mail: focalisa@hotmail.com
} 


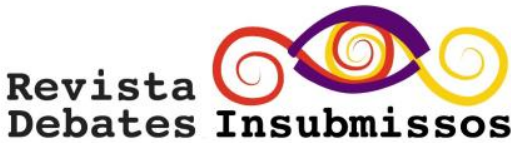

Saint Laurent que faz o figurino de Miriam; unido características de uma mulher forte, e clássica; trazendo uma conotação de empoderamento da personagem perante a trama.

Podemos perceber que o filme reflete os excessos dos anos 1980, época de constantes transformações culturais, frutos de uma efervescência pós-moderna, que exalta a multiplicidade de estilos musicais e cinematográficos perpassados pelas mídias. A Mtv estava em ascensão pela popularidade do videoclipe e a moda nunca havia sido tão diversa influenciada pelo fenômeno do bubble up, as subculturas também ditavam a moda chegando ao mainstream, as influências vinham de várias esferas, inclusive de tendências retrôs.

Tomamos como base de analise o figurino do personagem John Blaylock, em relação ao tempo e espaço, percebemos em suas vestimentas referências a trajes típicos de subculturas da década de 1980 como os yuppies e os góticos e de homens modernos da cidade de Nova York, além de uma inspiração no figurino de detetives de filmes noir das décadas de 1930 e 1940, que serve de referencial para o próprio homem elegante dos anos 1980, como aponta Crane: “ Nas décadas de 1980 e 1990, os modelos de comportamento na área de vestuários masculino eram as estrelas de cinema da década de 1930 a realeza britânica e notadamente, Fred Astaire e o Duck de Windsor". (2006. P .342)

Partindo destas constatações, interpretamos o vestuário de John (David Bowie) como para-realista já que ele agrega elementos registrados na década de 1980, entretanto há uma preocupação para que o figurino esteja de acordo com a narrativa do filme, no sentido de passar as características sócio-psicológicas do personagem em questão, retratando fases distintas do personagem, e se utilizando de elementos de subculturas diferentes, para ilustrar a figura do vampiro moderno.

\section{PERSONA}

Sobre a figura do David Bowie é sabido que em 1983 ele não só era um artista consagrado como também já havia se construído um mito em torno de sua imagem, desde o começo da fama com o sucesso de Space Odity, mais precisamente após encarnar sua primeira persona em 1972 Ziggy Stardust. 
A aparência excêntrica e andrógina de Ziggy sem dúvidas causou um impacto grande na cultura, influenciando toda estética da década de 1970, nos demais anos da década fícou claro o mérito por seu título de camaleão do Rock, já que Bowie encarnou outras personas como Alladin Sane em 1973 considerado por muitos uma extensão de Ziggy Stardust, Hallowen Jack em 1974, é interessante destacar que o mesmo era Punk em uma época onde não haviam Punks, as músicas desta fase retratavam um futuro pós apocalíptico, onde o caos era celebrado, em 1975 criou Thin With Duck um fascista que falava de amor de forma fria.

Em 1977 Bowie foi morar na Alemanha, onde gravou três discos que ficaram conhecidos como a "trilogia Berlim", foi uma época reflexiva em sua vida onde Bowie tentou afastar-se das drogas, do misticismo ao qual buscava por anos, em $1983 \mathrm{fez}$ seu quarto papel no cinema, vivendo o vampiro John, toda a carreira de David Bowie foi simbolicamente construída por sua excentricidade, ele foi precursor em vários âmbitos, musicalmente influenciou o pós punk, que foi influenciador estético para a subcultura gótica, a qual influenciou o figurino de seu personagem no filme, sendo assim é fácil ligar Bowie sempre a vanguarda, entretanto ele nunca deixou de ser versátil, atuando em filmes como "O homem que caiu da terra" de 1976 e "furyo, em nome da honra" de 1983.

\section{ANÁLISE DE CENAS}

\subsection{A caçada}

Denotação: O personagem de Bowie é apresentado em um club de estética punk, sua primeira imagem é um detalhe em seus óculos redondos na cor preta, o personagem tem cabelos pretos (o qual se revela ser uma peruca no fim da cena), ele usa paletó preto com um leve brilho acetinado, com camisa preta, acompanhadas por um relógio com a pulseira em couro e mostrador dourado, e um colar com pingente em ouro velho (o qual contém uma pequena lâmina afiada). A personagem de Denueve é apresentada ao espectador através de um detalhe em seus óculos prateado no estilo gatinho, Miriam usa um terno preto, com luvas pretas e detalhes em metal com o comprimento até o meio do braço, brincos com pingentes pretos, um 


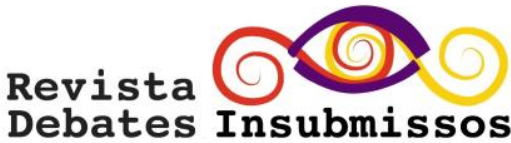

colar com pingente em ouro velho (do mesmo que John usa) e um macacão justo ao corpo compõe o look da personagem de Denueve.

Conotação: O figurino de Bowie representa a elegância Yuppie dos anos 1980, onde o terno, que é um traje tradicional ganha um toque de modernidade e sofisticação associadas ao brilho acetinado somado à cor preta que uni a estética yuppie a elementos da subcultura Gótica, podemos destacar o óculos que cumprem com o objetivo de passar o ar de mistério ao personagem. Miriam com seu terno com ombreiras cumpre a função de poder, em que se mostra no desenrolar do filme uma mulher forte, associada aos óculos que usa há a modernidade do prateado, e a classe com o seu cabelo preso em um coque impecável.

Descrição da Cena: (1,07 min- 6,06 min). Os personagens de Bowie e Denueve chegam a um club de estética punk, onde a banda Bauhaus está tocando Bela Lugosi, a câmera dá close em alguns detalhes como os óculos destes personagens, até serem mostrados em uma câmera baixa, passando a ideia de poder que estes personagens têm. Após encontrarem suas "prezas" no club, John e Miriam levam o casal de desconhecidos a uma casa, onde os seduzem e os matam para se alimentar de seu sangue. No decorrer da cena há uma metáfora em que o casal de vampiros é comparado a um macaco agressivo; com um jogo de cortes rápidos, cria-se uma tensão entre a sedução provocada pelos vampiros e o suspense pelo que vai acontecer ao casal de desconhecidos, suspense esse reforçado pela inserção de imagens de um macaco matando e se alimento de outro primata.

\subsection{Conflito}

Denotação: Após ter um anoite de insônia John está recostado na parede de seu quarto fumando um cigarro; tons brancos, janelas cobertas por cortinas brancas de um tecido esvoaçante, e uma cama com dossel conferem ao ambiente um luxo e sofisticação, o personagem usa um roupão preto com detalhes em vermelho por cima de seu pijama branco, após um deslocamento do personagem pelo quarto, há um close na face lateral do personagem, podemos notar agora a cor do seu cabelo natural (louro). 


\section{Revista \\ Debates Insubmissos}

Conotação: O personagem se encontra em um ambiente íntimo, ainda trajando roupas de dormir o que demonstra sua inquietude e fragilidade diante da situação que está para acontecer, isso é reforçado pôr planos detalhes em seu rosto, mostrando sua expressão.

Descrição da cena: (11,21 min-12,29 min). A cena é composta por alguns flashes do passado de John, que observa Miriam enquanto ela dorme, esses flashes demonstram certo saudosismo de sua vida quando ele ainda era humano, e sua lembrança da promessa feita por Miriam, a qual lhe diz que sua nova vida será para sempre.

\subsection{Frustração}

Denotação: Após perceber que está envelhecendo, John vai até a clínica Park West para conversar com a doutora Sara Roberts, a procura de ajuda. O personagem se apresenta trajando um sobretudo preto que vai até o meio de sua canela sobrepondo um casaco preto estampado e uma camisa azul clara, um chapéu preto, acompanhado de calça clara e sapatos pretos, usa óculos estilo aviador com lente incolor. (21,21 min-27,52 min).

Conotação: $\mathrm{O}$ uso de roupas predominantemente pretas mais uma vez conferem ao personagem um ar misterioso, o sobretudo típico de filmes noir e o chapéu reforçam essa ideia além de representarem a elegância condizente com o personagem, após envelhecer cada vez mais rápido, John tem uma aparência cansada e frágil, o que se opõe a ideia de poder existentes no início do personagem. Os óculos com lentes incolores permitem que o espectador veja a angústia no olhar de John e sua decadência perante o seu envelhecimento.

Descrição da Cena: (21,21 min-27,52 min). Após chegar de taxi a clínica, John adentra no prédio e vai procurar pela Dr. Sara, em seu percurso a procura pela médica John passa por alguns macacos que estão em jaulas. Há um corte na cena e a doutora Sara aparece em seu escritório conversando com uma funcionária da clínica, a mesma fica ressaltada quando percebe a presença de John em seu consultório. Depois de um rápido diálogo entre John e Sara o mesmo a aguarda na sala de espera da clínica, a sequência a seguir é feita com cortes alternando entre John e a doutora Sara a observar um macaco que está a envelhecer de forma bastante rápida. Essa sequência de cortes alternando entre John, Sara, e o macaco cria uma metáfora sobre o 


\section{Revista \\ Debates Insubmissos}

envelhecimento do animal, e o envelhecimento acelerado de John; após esperar pela doutora por duas horas, John se retira da clínica, mas antes ele procura a doutora Sara para mostrar-lhe o qual rápido está envelhecendo, fazendo com que Sara se espante com o caso que está em sua frente.

\subsection{Redenção}

Denotação: O personagem aparece sentado em uma poltrona em um canto da sala de piano, usando um paletó e calças bege, acompanhados de uma camisa azul claro, cinto de couro marrom e sapatos brancos. Miriam utiliza um look composto por uma saia na cor preta, acompanhada por uma acamisa de alfaiataria na cor grafiti com um leve brilho acetinado, meiacalça na cor preta, botas de cano curto pretas.

Conotação: John se apresenta no auge de sua fragilidade, como um senhor fraco e cansado; suas roupas que outrora lhe traziam um ar de mistério e sofisticação, agora o fazem ter uma aparência comum e humana. Em contra ponto Miriam está elegante e impecável, tendo isso reforçado em comparação ao seu companheiro. A fragilidade de Johnse torna mais explicita a partir do memoneto que ele não consegue mais andar e tem de ser carregado nos braços por Miriam, a qual o leva para o lugar onde ele "passará" a eternidade definhando.

Descrição da cena: (39,39 min- 47,52 min). Miriam encontra John sentando com a postura curvada em uma poltrona num canto da sala, o personagem está envolto na escuridão, há apensa um foco de luz na sala. Após implorar para que Miriam o mate, a personagem se retira da sala e vai até o incinerador onde Joh colocou sua última vítma, John apersegue e continua a pedir para que ela o mate; ele está fraco e acaba rolando pela escada, e tem de ser amparado por Miriam que o pões no braços e o leva para o sótão da casa, um lugar com aurea misteriosa, composto de pôr um luz central a qual está localzada no tento, criando um círculo iluminado que está circundado por cortina de tecido esvoaçante e transparente, há ainda a presença de vários pombos e alguns caixões. Miriam deposita John em um caixão, o mesmo mostra sua total fragilidade e decadência ao urina nas calças; enquanto Miriam fecha o caixão John a chama com um voz embargada e pouco auditível, em um sinal de pedido de ajuda. 


\section{CONSIDERAÇÕES FINAIS}

Como fruto da cultura pop vingente, o filme Fome de viver traz consigo uma carga simbólica, atrelada a moda, produção cultural, e ideologias vinculadas a época de sua produção (1980), sendo um retrato da busca pelo subversivo, futurista, do espírito jovem. Com as análises semiológicas, foi possível compreender a personalidade de john, fazendo analogias em relação a seu figurino e comportamneto, podendo assim atrelar valores de uma época.

\section{REFERÊNCIAS}

ADORO CINEMA. Fome de viver. Adoro Cinema,2016. Disponível em: <http://www.adorocinema.com/filmes/filme-30460/> Acesso em: 06 de maio de 2021 ASH, Daniel. J, David. HASKINS, Kevin. MURPHY, Peter. Bela Lugosi's Dead (Bela Lugossi não está morta) - Bauhaus. Letras, S/A. Disponível em: <https://www.letras.mus.br/bauhaus/3391/traducao.html > Acesso em: 06 de maio de 2021 CENTRO DE ENTRETENIMENTO Eo vídeo levou. Milena Canonero: Itália (1946) Figurinistas Importantes. Eo vídeo levou,S/A. Disponível em:

$<$ http://www.eovideolevou.com.br/locacao/filme/assuntos.asp?ca=1186 > Acesso em : 06 de maio de 2021

CRANE, Diana. A Moda e seu papel social classe, gênero e identidade das roupas. São Paulo: Editora Senac São Paulo, 2006.

DYNALOT. Yves - Saint - Laurent: um genio imortal. Lado-m.com, S/A.Disponível em: < http://www.lado-m.com/yves-saint-laurent-um-genio-imortal/> Acesso em: 06 de maio de 2021

\section{REFERÊNCIAS DIGITAIS}

SIGNIFICADOS. Significado de Empoderamento. Significados, 28 de Maio de 2016. Disponível em: <http://www.significados.com.br/empoderamento/> Acesso em: 06 de maio de 2021

SPECTRUM GOTIC. Biografia Bauhaus. Spectrum Gothic - Ad Perpetuam rei memoriam, S/A. Disponível em: < http://www.spectrumgothic.com.br/musica/bandas/bauhaus/bio_bauhaus.htm> Acesso em: 06 de maio de 2021

Submetido em: 04/08/2020

Aprovado em: 15/12/2020 